\title{
CONCENTRAÇÃO SÉRICA DAS ENZIMAS CREATINOQUINASE, ASPARTATO AMINOTRANSFERASE E DEHIDROGENASE LÁTICA EM EQUINOS DA RAÇA CRIOULA
}

\author{
CK, AST AND LDH SERIC CONCENTRATION IN CRIOULO BREED HORSES
}

\author{
Elisiane Lourdes Da Cãs ${ }^{1}$ Aura Chaves Rosauro ${ }^{2}$ Carlos António Mondino Silva $^{3}$ \\ Karin Eriça Brass ${ }^{4}$
}

RESUMO

A concentração de creatinoquinase (CK), aspartato aminotransferase (AST) e dehidrogenase lática (LDH) foi determinada em amostras de soro obtidas de 60 equinos da raça Crioula: 20 éguas mantidas no pasto (Grupo A), 20 equinos em treinamento (Grupo B) e 20 participantes da competição do "Freio de Ouro de 1997" em Esteio - RS (Grupo C), dos quais foram colhidas amostras 24 a 48 horas antes do início da competição e 24 e 48 horas após a mesma. Não houve variação significativa na $\mathrm{LDH}$. $O$ grupo $B$ apresentou concentrações de $C K$ e AST mais elevadas $(p<0,05)$ que os grupos $A$ e $C$, indicando uma adaptação ao exercício. Quarenta e oito horas após a competição, a CK alcançou a sua concentração mais baixa e, a AST, a mais elevada. Isso indica que a CK e AST são mais informativas para avaliação da função muscular que a $\mathrm{LDH}$. As fêmeas apresentaram concentração de CK mais elevada $(p<0,05)$ que os machos. Houve variação significativa com relação à classificação dos equinos em competição, mostrando uma tendência a valores mais baixos nas primeiras colocações, o que indicaria a condição dos equinos melhor preparados.

Palavras-chave: $C K, A S T, L D H$, equinos.

\section{SUMMARY}

Creatine Kinase (CK), Aspartate Aminotransferase (AST) and Lactic Dehidrogenase (LDH) concentration was determined in serum samples obtained from 60 horses of the Criollo breed: 20 mares managed on pasture (Group A), 20 horses in training (Group B) and 20 horses participating of the Freio de Ouro 1997 competition (Group C), where samples were collected 24-48 hours before competition and 24 and 48 hours there after. There was no difference in $L D H$ values between groups. Group B horses had higher ( $p<0.05)$ CK and AST serum concentrations than horses in groups $A$ and $C$, indicating an adaptation to exercise. Forty eight hours after competition, $C K$ values were lowest and AST highest. CK and AST were more informative than $\mathrm{LDH}$ in evaluating muscular function. Females had higher $C K$ activity $(p<0.05)$ than males. There were significam diferences related to final outcome of competition with a trena of lower values in the first places, indicating the athletic condition of the best horses.

Key words: $C K, A S T, L D H$, horses.

\section{INTRODUÇÃO}

A utilização crescente do equino em esportes e lazer, nos últimos anos, tem levado, também, a uma diversificação nas provas em que esses participam e a uma maior exigência em termos de performance. Os sinais clínicos presentes em distintas alterações musculares são semelhantes e bastante inespecíficos; por isso, quando isolados, têm limitado valor diagnóstico, requerendo, frequentemente, o uso de exames laboratoriais complementares. Esses podem incluir, além do exame bioquímico para determinação das enzimas de função muscular, o mais comumente utilizado em medicina equina, o exame histológico e histoquímico de biópsias musculares, termografia e eletromiografia (HARRIS, 1998). As enzimas, cujas concentrações séricas devem ser determinadas quando de disfunções musculares, são a CK, a AST

\footnotetext{
${ }^{1}$ Médico Veterinário, MSc., Autônomo.

${ }^{2}$ Acadêmico do Curso de Medicina Veterinária, Universidade Federal de Santa Maria (UFSM).

${ }^{3}$ Médico Veterinário, Doutor, Professor Titular, Departamento de Clínica de Grandes Animais, UFSM.

${ }^{4}$ Médico Veterinário, Doutor, Professor Adjunto, Departamento de Clínica de Grandes Animais, UFSM, Faixa de Camobi, Km9, 97105-

900, Santa Maria - RS. E-mail: kebrass@ lince.hcv.ufsm.edu. Autor para correspondência.
}

Recebido para publicação em 23.04.99. Aprovado em 20.10.99 
e a LDH. Porém, os valores citados na literatura para essas enzimas apresentam ampla variação, considerando diferentes autores. Há também diversos fatores que podem alterar os resultados das análises, entre os quais se encontram os inerentes aos animais, como por exemplo idade, sexo e raça (MESSER, 1995). O presente trabalho teve por objetivo avaliar as concentrações das enzimas séricas CK, AST e LDH em equinos da raça Crioula submetidos a dois diferentes regimes de exercício, comparando-as com as concentrações avaliadas em éguas da mesma raça mantidas a pasto.

\section{MATERIAL E MÉTODOS}

Foram colhidas amostras de sangue em tubos de vidro com vácuo VACUUM $\mathrm{II}^{\mathrm{a}}$, sem anticoagulante, de 60 equinos da raça Crioula divididos em três grupos: Grupo A - 20 animais (éguas com idade entre 4 e 15 anos) mantidos no pasto por um período mínimo de 30 a 60 dias; Grupo B - 20 animais em treinamento (12 fêmeas com idade entre 2,5 e 8 anos e 8 machos com idade entre 1,5 e 20 anos). O treinamento consistia de um aquecimento inicial de 5 a 10 minutos em que os animais realizavam exercícios a passo, em uma andadura intermediária entre passo e trote (tranco) e trote. Depois, eram realizadas evoluções em círculo e em ' 8 ' a galope e, a seguir, arrancadas em alta velocidade por uma distância de 40 a 50 metros, seguidas de "esbarrada". Esses equinos também trabalhavam com gado, de maneira intercalada com outras atividades físicas. $\mathrm{Na}$ última etapa do treinamento, os equinos realizavam novamente exercícios de andadura. $\mathrm{O}$ período total de atividade física variava entre 45 e 75 minutos diários. Os equinos dos grupos A e B eram provenientes do "Centro de Treinamento de Crioulos", situado na Fazenda Capela no município de Bagé - RS; Grupo C - 20 equinos em competição ( 10 fêmeas com 5 a 11 anos de idade e 10 machos com 4 a 10 anos), participantes da "Prova Final do XVI Freio de Ouro" durante a Exposição Internacional de Esteio (Expointer/97), no município de Esteio, RS. Desse grupo, foram colhidas três amostras: antes da competição (24 a 48 horas) e após o encerramento (24 e 48 horas). A classificação final desses equinos foi tabulada.

Nos grupos A e B, foi realizada apenas uma coleta de sangue. Após a retração do coágulo, o soro obtido foi separado 2 a 4 horas após a coleta, congelado e, posteriormente, submetido à determinação da concentração das enzimas CK, AST e LDH. A concentração da enzima CK foi determinada pelo método CK-NAC ativado, utilizando o kit CK-NAC Labtest ${ }^{\mathrm{b}}$, com leitura no enzimômetro Quick-lab ${ }^{0}$. A concentração da AST foi determinada usando o kit para AST da Labtest e a sua leitura também foi realizada no enzimômetro. Para avaliar a concentração da LDH foi utilizado o kit para LDH pelo método colorimétrico da Labtest com leitura no espectrofotômetro Spectronic 2100 Clinicai Analyser. As técnicas utilizadas para a dosagem da atividade das enzimas CK, AST e LDH seguiram a indicação do laboratório de origem dos kits.

O delineamento experimental utilizado foi de blocos ao acaso incompletos de um experimento fatorial $2 \times 5$, com números variados de repetições. As análises estatísticas incluíram análise da variância, teste $\mathrm{F}$ e teste $\mathrm{t}$ de Student (PDIFF) para comparar as médias dos tratamentos. Foi realizada análise de covariância, tomando a idade como covariável. Para análise da classificação dos equinos na prova e dos valores enzimáticos, foi utilizado o modelo fatorial $10 \times 2$ (10 classificações $\times 2$ sexos) em um delineamento experimental inteiramente casualizado com 3 repetições. Foi feita a comparação de médias ajustadas pelo teste $\mathrm{t}$ de Student (PDIFF). As análises estatísticas foram realizadas utilizando o pacote estatístico Statistical Analysis System - SÃS (1990).

\section{RESULTADOS}

A concentração média de CK no grupo A foi de $144 \mathrm{U} / \ell$. A concentração de CK mais elevada ocorreu no grupo B, alcançando média de 206U/ $\ell$. Nas amostras do grupo C, as colhidas 24 a 48 horas antes do início das provas apresentaram uma

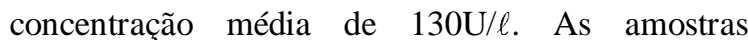
colhidas 24 horas após a prova apresentaram média de $148 \mathrm{U} / \ell$ para concentração dessa enzima. Os valores mais baixos para CK $(X=99 \mathrm{U} / \ell)$ foram encontrados nas amostras colhidas 48 horas após a realização das provas (Tabela 1). Os resultados da concentração sérica da CK no grupo B foram significativamente mais elevados $(\mathrm{p}<0,05)$ quando comparados com os outros grupos, assim como a queda desses valores também foi significativa ( $\mathrm{p}<0,05)$ nas amostras colhidas 48 horas após o encerramento das provas pêlos equinos do grupo $\mathrm{C}$.

Nas dosagens da concentração da AST, os valores séricos mais baixos foram observados no grupo $\mathrm{A}(\mathrm{X}=218 \mathrm{U} / \ell)$. O grupo $\mathrm{B}$ apresentou média

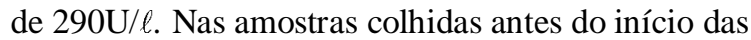
provas, no grupo $\mathrm{C}$, a média foi de $277 \mathrm{U} / \ell$, aumentando nas amostras colhidas no dia seguinte ao encerramento das provas $(X=297 \mathrm{U} / \ell)$. A concentração da AST alcançou os valores mais elevados 48 horas após a competição (X= $313 \mathrm{U} / \ell)$ (Tabela 1). O valor da AST no grupo A apresentou diferença significativa $(p<0,05)$ frente ao grupo B. 


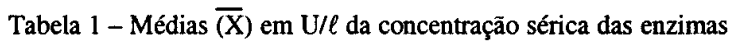
CK, AST e LDH em eqüinos da raça Crioula, nos grupos A, B e C.

\begin{tabular}{cccc}
\hline Grupos & CK & AST & LDH \\
\hline A & $144^{\mathrm{b}}$ & $218^{\mathrm{b}}$ & 675 \\
& $(114-174)$ & $(174-262)$ & $(577-774)$ \\
\hline B & $206^{\mathrm{a}}$ & $290^{\mathrm{a}}$ & 655 \\
& $(180-232)$ & $(252-328)$ & $(570-740)$ \\
\hline C & & & \\
antes das provas & $130^{\mathrm{b}}$ & $277^{\mathrm{a}}$ & 622 \\
& $(100-159)$ & $(235-320)$ & $(527-717)$ \\
24h após encerramento & $148^{\mathrm{b}}$ & $297^{\mathrm{a}}$ & 580 \\
& $(119-178)$ & $(254-340)$ & $(484-675)$ \\
48h após encerramento & $99^{\mathrm{c}}$ & $313^{\mathrm{a}}$ & 612 \\
& $(70-128)$ & $(271-356)$ & $(517-707)$ \\
\hline F & 10,41 & 3,06 & 0,72 \\
p< & 0,0001 & 0,0213 & 0,5787 \\
\hline
\end{tabular}

a,b.c. Nas colunas, médias seguidas de letras diferentes são significativamente diferentes entre si pelo teste $t$ de Student, PDIFF $(\mathrm{p}<0,05)$.

O grupo A apresentou a média $(675 \mathrm{U} / \ell)$ mais elevada na dosagem de $\mathrm{LDH}$, seguidos do grupo B com valor médio de $655 \mathrm{U} / \ell$. O grupo $\mathrm{C}$ apresentou concentrações séricas mais baixas tanto nas amostras colhidas 24 a 48 horas antes da realização das provas $(\mathrm{X}=622 \mathrm{U} / \ell)$ como nas colhidas $24(\mathrm{X}=5 \mathrm{SOU} / \ell)$ e 48 horas $(\mathrm{X}=612 \mathrm{U} / \ell)$ após a realização das provas (Tabela 1). As variações na concentração da enzima LDH encontradas entre os grupos não foram significativas.

As fêmeas apresentaram valores médios

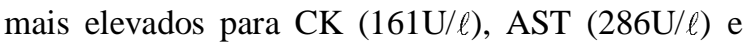

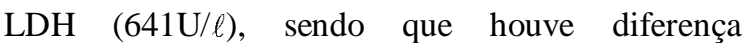
significativa em relação ao sexo $(\mathrm{p}<0,05)$ para a concentração da enzima CK. Nos machos, encontraram-se valores médios de $129 \mathrm{U} / \ell$ para CK,

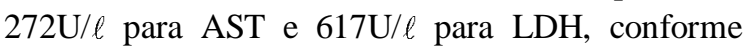
pode ser observado na tabela 2 .

Dos equinos do grupo $\mathrm{C}$ cujos valores enzimáticos foram determinados, 3 machos e 7 fêmeas se classificaram para a final. Na tabela 3, observa-se a variação significativa ocorrida com relação à classificação dos equinos do grupo $\mathrm{C}$ de ambos os sexos para as enzimas CK $(\mathrm{p}<0,0131)$ e LDH $(\mathrm{p}<0,0134)$ e 0,49 altamente significativa para
Tabela 2 - Médias em U/ $\ell$ da atividade das enzimas CK, AST e LDH em equiinos machos e fêmeas da raça Crioula.

\begin{tabular}{|c|c|c|c|c|}
\hline Sexo & $\mathbf{n}$ & CK & AST & LDH \\
\hline $\mathbf{M}$ & 38 & $\begin{array}{c}129^{\mathrm{b}} \\
(106-152)\end{array}$ & $\begin{array}{c}272 \\
(239-306)\end{array}$ & $\begin{array}{c}617 \\
(542-692)\end{array}$ \\
\hline F & 62 & $\begin{array}{c}161^{\mathrm{a}} \\
(138-184)\end{array}$ & $\begin{array}{c}286 \\
(253-320)\end{array}$ & $\begin{array}{c}641 \\
(566-716)\end{array}$ \\
\hline Média & 100 & 148 & 274 & 631 \\
\hline F & - & 5,38 & 0,49 & 0,28 \\
\hline $\mathrm{p}<$ & - & 0,0229 & 0,4852 & 0,5993 \\
\hline $\mathrm{CV}$ & - & 32,53 & 25,73 & 24,91 \\
\hline
\end{tabular}

a,b, Nas colunas, médias seguidas de letras diferentes são significativamente diferentes entre si pelo teste $t$ de Student, PDIFF $(p<0,05)$.

a AST $(p<0,0001)$. As concentrações das três enzimas dos animais, macho e fêmea, melhor classificados, apresentaram valores mais baixos que a maioria dos demais competidores, ou não diferiram significativamente de alguns deles.

\section{DISCUSSÃO}

Segundo GUPTA et al. (1994), a raça Puro Sangue de Corrida (PSC) apresenta valores enzimáticos mais elevados que outras raças. Isso, porém, não se aplica à raça Crioula (Tabela 1), na qual se observam valores superiores aos citados por SOMMER \& STYRIE (1990) e DA CÁS (1998) para animais PSC em regimes semelhantes ao do grupo B do presente trabalho.

Houve elevação significativa dos valores de CK ( $\mathrm{p}<0,0001)$ e AST $(\mathrm{p}<0,05)$ nos equinos do grupo B quando comparados aos do grupo A. Equinos em estágios distintos de condicionamento e submetidos a diferentes programas de treinamento, quando avaliados após o exercício, apresentam alterações na concentração das enzimas CK, AST e LDH (ROSE et al., 1983; FREESTONE et al., 1989), entretanto, somente a CK tem especificidade absoluta para o tecido muscular. Segundo RUDOLPH et al. (1993), o comportamento da AST é variável durante o treinamento. HARRIS (1998) afirmou que os efeitos do exercício sobre a concentração dessas enzimas dependem do estado de saúde dos animais, da intensidade e duração do exercício ao qual são submetidos, bem como do ambiente. Quando o período de duração do exercício 


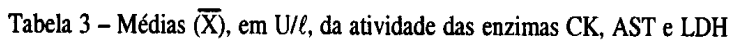
nas amostras coletadas antes, 24 e 48 horas após o encerramento da competição de acordo com a ordem de classificação final (os finalistas estão em negrito) dos eqüinos do grupo $\mathrm{C}$.

\begin{tabular}{|c|c|c|c|c|c|c|}
\hline \multirow[b]{2}{*}{ Classificação } & \multicolumn{2}{|c|}{$\mathrm{CK}^{*}$} & \multicolumn{2}{|c|}{$\mathrm{AST}^{* *}$} & \multicolumn{2}{|c|}{ LDH $^{*}$} \\
\hline & M & F & $\mathrm{M}$ & F & M & $\mathrm{F}$ \\
\hline 1 & $86^{\mathrm{cd}}$ & $102^{\text {bed }}$ & $210^{c}$ & $264^{\mathrm{c}}$ & $631^{\mathrm{bc}}$ & $507^{\mathrm{bc}}$ \\
\hline 2 & $79^{d}$ & $156^{\mathrm{ab}}$ & $210^{\mathrm{c}}$ & $291^{\mathrm{bc}}$ & $726^{\mathrm{ab}}$ & $868^{\mathrm{a}}$ \\
\hline 3 & $89^{\mathrm{cd}}$ & $165^{\mathrm{a}}$ & $247^{c}$ & $260^{\mathrm{c}}$ & $552^{\mathrm{bc}}$ & $715^{\mathrm{ab}}$ \\
\hline 4 & $102^{\text {bod }}$ & $137^{\text {abcod }}$ & $444^{2}$ & $236^{\mathrm{c}}$ & $649^{\mathrm{b}}$ & $734^{\mathrm{sb}}$ \\
\hline 5 & $162^{\mathrm{a}}$ & $143^{\text {abc }}$ & $360^{\mathrm{b}}$ & $399^{\mathrm{ab}}$ & $529^{\mathrm{bc}}$ & $737^{\mathrm{ab}}$ \\
\hline 6 & $97^{\mathrm{cd}}$ & $143^{\text {abc }}$ & $204^{c}$ & $239^{c}$ & $525^{\mathrm{bc}}$ & $618^{b}$ \\
\hline 7 & $165^{\mathrm{a}}$ & $97^{\text {dd }}$ & $239^{\mathrm{c}}$ & $429^{\mathrm{ab}}$ & $471^{c}$ & $759^{\mathrm{ab}}$ \\
\hline 8 & $170^{\mathrm{a}}$ & $124^{\text {abced }}$ & $329^{\mathrm{bc}}$ & $318^{\mathrm{bc}}$ & $633^{b c}$ & $486^{b c}$ \\
\hline 9 & $94^{\mathrm{dd}}$ & $100^{\text {bed }}$ & $295^{x}$ & $259^{\mathrm{c}}$ & $527^{b c}$ & $492^{\mathrm{bc}}$ \\
\hline 10 & $100^{\mathrm{bed}}$ & $116^{\text {abed }}$ & $262^{c}$ & $270^{c}$ & $516^{b c}$ & $510^{\mathrm{bc}}$ \\
\hline
\end{tabular}

\footnotetext{
${ }^{a, b, c, d}$ Nas coluna, médias seguidas de letras diferentes são significativamente diferentes entre si pelo teste $t$ de Student (PDIFF).

${ }^{*} \mathrm{p}<0,05$.

$* * p<0,0001$.
}

é mantido constante, a intensidade do exercício determina o aumento na concentração de CK.

Um programa de treinamento adequado, que se ajusta ao condicionamento físico do equino, não leva a um aumento acentuado na concentração das enzimas de função muscular (BOGIN et al., 1989). Os valores enzimáticos encontrados, apesar de aumentados (menos que o dobro do valor do grupo A) ainda permanecem dentro dos parâmetros fisiológicos estabelecidos por KERBER \& TRINDADE (1993), sugerindo uma adaptação ao programa de exercício a que vinham sendo submetidos.

A tabela 1 mostra que nas amostras colhias, antes do início das provas, dos equinos do grupo $\mathrm{C}$, os valores de $\mathrm{CK}$, AST e LDH determinados foram mais baixos que nos equinos do grupo $\mathrm{B}$, embora, significativamente, apenas a CK. Isso indica que, com a adaptação ao exercício durante o treinamento, ocorre um declínio seguido de estabilização dos valores enzimáticos conforme citou SOMMER (1983). O acompanhamento das concentrações enzimáticas em equinos em treinamento pode auxiliar na sua avaliação, bem como permitir a detecção precoce de alterações musculares ainda subclínicas (VALBERG et $\boldsymbol{a l}$., 1993).

Nas amostras obtidas 24 horas após a competição, ocorreu uma elevação, não significativa, da CK e AST. Após 48 horas do encerramento das provas, a concentração da CK estava significativamente mais baixa $(\mathrm{p}<0,05)$ que aquela determina da antes do início da competição e, a concentração sérica da AST continuou subindo de forma não significativa. As concentrações séricas de LDH não variaram significativamente com o exercício, indicando que a CK e a AST são mais informativas na avaliação da função muscular. A intensificação da função celular, como ocorre durante o exercício, ou em casos de dano celular, leva a um consumo maior de substrato, resultando em aumento da permeabilidade da membrana (HARRIS, 1998). O comportamento observado para a CK deve-se à rápida liberação dessa enzima na circulação, resultante de sua localização citoplasmática, alcançando o pico máximo seis horas após a alteração celular (COFFMAN, 1979a; COFFMAN, 1979b). Segundo ROSE et al. (1983), a CK apresenta uma elevação rápida após exercício máximo e submáximo. $\mathrm{O}$ aumento na concentração sérica das enzimas de função muscular seria uma onsequência fisiológica do tipo de exercício executado. Já na AST, pela localização citoplasmática e mitocondrial (BOGIN et al., 1989; KRAMER, 1989; HARRIS, 1998), a elevação é mais lenta, alcançando concentrações máximas 12 a 24 horas após uma alteração celular (FREEDLAND \& KRAMER, 1970; COFFMAN, 1979a). HARRIS (1998) observou pequeno aumento na concentração da enzima AST após diferentes tipos de atividade física.

$\mathrm{O}$ valor médio de $\mathrm{CK}$ foi significativamente $(p<0,05)$ mais elevado nas fêmeas que nos machos (Tabela 2). Isso não foi observado nos valores de AST e LDH. Como neste trabalho, HARRIS et al. (1990) encontraram valores mais elevados de CK e AST nas fêmeas que nos machos, especialmente nas potrancas. Tal fato pode estar relacionado à atividade enzimática mais elevada e/ou à remoção mais lenta da circulação, ou ainda, a uma maior sensibilidade a agressões que alteram a permeabilidade das fibras musculares, resultando em maior incidência de rabdomiólise em fêmeas.

Houve variação significativa nas concentrações enzimáticas de acordo com a colocação final dos equinos do grupo C (Tabela 3). Nos equinos que participaram da final, os valores enzimáticos médios das 3 colheitas realizadas por equino foram mais baixos ou não diferiram estatisticamente dos valores mais baixos nos equinos, macho e fêmea, melhor classificados. Como a amostragem foi pequena seria fundamental avaliar um maior número de equinos, a fim de verificar até que ponto esses resultados se confirmam. É importante salientar que, como as duas últimas amostras foram colhidas 24 e 48 horas após o encerramento da competição, aqueles eqüinos 
que não se classificaram para a final terminaram as provas um dia antes dos demais.

\section{CONCLUSÕES}

Os resultados obtidos permitem concluir que equinos da raça Crioula, em fase de adaptação ao treinamento apresentam elevação dos valores séricos das enzimas CK e AST. Com a progressão do treinamento, ocorre declínio e estabilização dos mesmos. As enzimas CK e AST, nos equinos da raça Crioula, são mais informativas para avaliação da função muscular. A atividade da CK é mais elevada nas fêmeas que nos machos.

\section{FONTES DE AQUISIÇÃO}

a Labnew Indústria e Comércio Ltda. Rua Silva Mendes, 28. Campinas-SP, 13032-720, Brasil.

${ }^{\mathrm{b}}$ Labtest Sistemas Diagnósticos Ltda. Av.Isabel Bueno, 948. Belo Horizonte-MG, 31270-000, Brasil.

c Drake Eletrônica e Comércio Ltda. Biolife Comércio e Representações Ltda. Rua Vicente Ferreira Gomes, 174. Porto Alegre - RS, 9111 0-420, Brasil.

d Baush \& Lomb. Milton Roy Company - Analytical Products Division. 820 Lunden Avenue Rochester. New York, 14625, EUA.

\section{REFERÊNCIAS BIBLIOGRÁFICAS}

BOGIN, E., OTTO, F., IBÀNEZ, A. Patologia clínica veterinária. Assuncíon : Maknografic, 1989. 192p.

COFFMAN, J. Enzimology - part 1, p.1644-1649, 1979a.

COFFMAN, J. Enzimology - part 2. Equine Practice, v. 12, n.8, p.1791-1795,1979b.

DA CÁS, E.L. Atividade sérica das enzimas CK, AST e DHL em equinos. Santa Maria, 1998. 62p. Dissertação (Mestrado em Medicina Veterinária) - Programa de Pós-graduação em Medicina Veterinária, Universidade Federal de Santa Maria, 1998.

FREEDLAND, R.A., KRAMER, J.W. Use of serum enzymes as aids to diagnosis. Research Veterinary Science, v.14, p.6169, 1970.
FREESTONE, J.F., KAMERLING, B.S., CHURCH, G, et al. Exercise induced changes in creatine kinase and aspartate aminotransferase actívides in the horse: effects of conditioning, exercise tests and acepromazine. Journal of Equine Veterinary Srience, v.9, n.5, p.275-280,1989.

GUPTA, A.K., VARSHNEY, J.P., UPPAL, P.K. Comparative studies on biochemical Índices in difierent breeds of equines. Indian Veterinary Journal, v.71, n.1, p.26-30,1994.

HARRIS, P.A. Diseases musculoskeletal. m: REED, S.M., BAYLY, W.M. Equine internai medicine. Philadelphia : Saunders, 1998. cap.8,p.371-426.

HARRIS, P.A., SNOW, D.H., GREET, T.R.C., et al. Some factors influencing plasma AST/CK activities in thoroughbred racehorses. Equine Veterinary Journal. Suplemment 9, p.66-71,1990.

KERBER, C.E., TRINDADE, A.A. Manual de apoio ao veterinário clínico. São Paulo: Paddock, 1993. 35p.

KRAMER, J.W. Clinicai enzymology. In: KANEKO, J.J. Clinicai biochemistry of domestic animais. 4.ed. San Diego: Academia, 1989. cap.13,p.338-363.

MESSER, N.T. The use of laboratory tests in equine practice Veterinary clinics of North América: equine practice, v. 11, n.3,p.345-350,1995.

ROSE, RJ., HODGSON, D.R., SAMPSON, D. et al. Changes in plasma biochemistry in horses competing in a $160 \mathrm{Km}$ endurance ride. Australian Veterinary Journal, v.60, n.4, p.101-105,1983.

RUDOLPH, W., GOIC, M., MATTA, S., et al. Variación de Ias isoenzimas de dehidrogenasa láctica posterior a un ejercicio en equinos fina sangre de carrera con diferentes períodos de entrenamiento. Archivos de Medicina Veterinária, v. XXV, n.1, 1993.

SOMMER, H. Blood profile testing in racehorses. Equine Practice, v.5, n.10, p.21-27, 1983.

SOMMER, H., STYRIE, J. Bestimmung der referenzbereiche einiger enzyme, stoffwechselmetaboliten und núneraistoffe im blutplasma von pferden unterschiediicher rassen und Nutzungsformen. Tierarztliche Umschau, v.45, p.331-337, 1990 .

VALBERG, $\mathrm{S}$, HÃGGENDAL, J, LINDHOLM, A Blood chemistry and skeletal muscle metabolic response to exercise in horses with recurrent exertional rhabdomyolysis. Equine Veterinary Journal, v.25, p.17-22, 1993. 